\title{
Téoros
}

Revue de recherche en tourisme

\section{Quand l'État arrivera-t-il en ville ?}

\section{Vers la sortie du bois}

\section{Jean Décarie}

Volume 3, numéro 2, juillet 1984

L'intervention étatique dans le domaine du tourisme : premiers

coups de sonde

URI : https://id.erudit.org/iderudit/1080804ar

DOI : https://doi.org/10.7202/1080804ar

Aller au sommaire du numéro

\section{Éditeur(s)}

Université du Québec à Montréal

ISSN

0712-8657 (imprimé)

1923-2705 (numérique)

Découvrir la revue

Citer cet article

Décarie, J. (1984). Quand l'État arrivera-t-il en ville ? Vers la sortie du bois.

Téoros, 3(2), 30-30. https://doi.org/10.7202/1080804ar d'utilisation que vous pouvez consulter en ligne.

https://apropos.erudit.org/fr/usagers/politique-dutilisation/ 
Vers la sortie du bois

\title{
Quand I'État arrivera-t-il en ville?
}

\author{
par Jean Décarie*
}

Après une vingtaine d'années d'une upratique de l'Étatw dans le domaine du tourisme, qui remplaçait le traditionnel laisser-faire libéral en la matière, I'ancienne equation chasse et pêche/tourisme externe, par une préoccupation sociale et nationale, par le développement de structures mi-democratiques, mi-technocratiques, il est sans doute temps, devant les défis nouveaux de l'après-crise, de s'interroger sur le rôle de l'État dans l'élaboration du produit et des pratiques touristiques au Québec.

Le tourisme est un phénomène complexe, paradoxal, mouvant : toute politique à son endroit doit épouser et appuyer ses contours et ses contradictions. Une politique du tourisme, comme une politique du loisir, de l'environnement ou de la culture, est forcément une politique au deuxième degré. II ne suffit pas d'implanter des équipements, de cráer un domaine foncier, d'aménager des espaces. Au contraire peut-être, c'est surtout sur l'aménagement du temps, sur' l'organisation sociale, sur la négociation de participations qu'une telle politique doit faire porter le gros de ses efforts.

Le paradoxe touristique veut, en effet, que le tourisme soit bien une exploitation primaire des ressources naturelles et culturelles du pays, territoire et nation, mais avec ceci de particulier, qu'au lieu d'exporter la production, on importe la consommation, ce qui donne lieu à une extraordinaire économie tertiaire de services et meme quaternaire, de culture et de communication. La valeur touristique, ce que le touriste valorise, n'est jamais la valeur intrinsèque des choses - les cunits de la forèt par exemple - mais bien leur valeur extrinsèque, leur beauté, qui est toujours forcément dans le regard, la valeur ajoutée, et ajoutée par lui, par son imagination créatrice suscitée, sollicitée par le paysage et, évidemment, par sa préparation et sa présentation.

La meilleure politique possible sera donc. en conséquence, non pas celle qui enferme cette imagination dans des

\footnotetext{
- Jean Decarie est conseiller en aménagament.
}

formules toutes faites, dans des zonages conventionnels, mais celle qui stimule le plus l'imagination du touriste et, partant, sa participation. A cet égard, la contribution des nationaux est aussi essentielle à lá définition et à l'élaboration même d'un produit touristique original, culturel, qui seul pourra, à son tour, attirer un tourisme étranger de qualité, venu par-dessus le marché, á proprement parler, apporter son tribut économique à une mise en valeur essentiellement sociale.

Ceci vaut tout spécialement pour les formules et les structures spatiales ou territoriales. Faute de contröler le temps et donc la demande, on a en effet pris l'habitude de se rabattre sur l'offre, de produire de l'espace, et ce, d'autant plus facilement que l'État possède déjà les terres de la Couronne où se déploie toute cette nature gratuite quil a longtemps tenu lieu de culture exportable aux touristes étrangers sinon aux Québécois eux-me̊mes.

Ce réflexe foncier, propriétaire et paternaliste, caractérise et confine encore aujourd'hui l'intervention de l'État. Politiciens et technocrates préferent toujours constituer, se constituer des domaines propres où l'on peut mieux contrôler les situations, mais qui se trouvent en mẹme temps à cautionner l'inaction ou à tout le moins a limiter les interventions à l'extérieur, sur tout le reste le plus important de la réalité anormales, en particulier sur le domaine habité et dans le milieu urbain où se situent la demande et les véritables besoins.

Ce que l'on investit et immobilise dans une théorie marginale de parcs nationaux, par exemple, ne rejoint jamais la pratique réelle et concrète des populations des régions centrales. Les parcs nationaux, par definition de conservation, la récréation étant une responsabilité locale ou régionale, doivent aussi par définition, rester l'exception, se limiter à l'exceptionnel et à l'intérêt national. La règle doit être d'organiser les milieux humains et urbains, ces concentrations culturelles qui, plus que toute nature morte, font l'objet de l'intérêt et de l'attrait touristiques.
Le haut niveau de complexité institutionnelle et environnementale des milieux habités interdit tout simplisme, tout unilatéralisme dans les interventions de l'Etat, Ce qui explique peut-être sa relative absence. Mais il faut souligner les efforts récents du gouvernement pour karriver en villes, adapter ces modes d'action à la réalité socio-spatiale d'une urbanisation post-industrielle. La loi 125 , qui lie le gouvernement aux municipalités et cellesci aux milieux par des processus de concertation et de consultation obligatoires, fournit un cadre général intéressant à cet égard. Le Livre blanc sur le loisir va dans le même sens, qui fait du citoyen le centre et de la municipalité le maître d'ceuvre du développement du loisir.

La politique des parcs urbains, annoncée pour la région de Montréal par le MLCP. devrait reprendre enfin, concrétiser et projeter encore davantage cette orientation. Elle doit non seulement viser á rattraper le retard et a mettre dans cette région, qui compte la moitié de la populátion du Québec, autant de ressources quion en a consacrées dans le reste de la province, mais surtout aे instaurer de nouveaux modes d'intervention, à redonner aux municipalités et aux milieux les moyens de contrôle sur le processus de production de leur environnement, de leur cadre et de leur qualité de vie.

II ne s'agit pas d'implanter de nouveaux parcs traditionnels pour rejoindre une norme internationale elle-même définie suivant des formules anciennes, ce qui serait de toute façon financièrement impossible. II s"agit plutôt de créer des parcs, ou un parc au second degré, une zone portant servitude sur tout le territoire en fonction d'une primauté, reconnue d'intérêt public, de la qualité de vie et du cadre de vie, de l'habitat.

II s'agit d'associer les populations, municipalités et milieux, à la définition et à la gestion de leurs espaces de loisir, par des sociétés de développement qui vont afaire le parcs à leur image, ce qui est encore la meilleure facon de afaire du tourismen et, sans doute, d'attirer, a l'envi, le tourisme étranger. $f$ 